\section{P6.20 MANAGING HIVIAIDS COMMUNITY NETWORK CARE IMPORTANT STRATEGY MOBILISATION}

${ }^{1}$ Ronald Ondari, ${ }^{2}$ Sarah Nyaboke, ${ }^{3}$ Shawn Mandere, ${ }^{4}$ Andrew Ondari. ${ }^{1}$ Highlands Community Assistance Rogramme (HICA), Nairobi, Kenya; ${ }^{2}$ Rescue Hoe International, Nairobi, Kenya; ${ }^{3}$ Mandere Trust Fund, Nyamira, Kenya; ${ }^{4}$ St. Ondari Ondari Memorial and Resource Centre, Nyamira, Kenya

\subsection{6/sextrans-2017-053264.671}

Introduction An emergency of strange disease? Many sick people visited had similar signs and symptoms. Christians, church pastor and physician visited, prayed and held the patients hand as they were praying. All interventions tried curbing these emerging diseases were in vain, later it was found to be incurable HIV. This was birth of Rescue Hope International (RHI), a community non-governmental organisation applying community network for care fighting HIV/AIDS.

Methods In September 2002, 10 community volunteers successfully completed their treatment after training in TB management to support, supervisor and monitor new clients on treatment at a ratio of $1: 14$ clients. After introduction of ARVs in 2004, 15 TB supporters were trained in home-based care, management of patients on ARV medication and basic knowledge of palliative care in partnership of ministry of health $(\mathrm{MOH})$ thus becoming; Community ARV TB Treatment Supporters (CATTS).Being first contact of new clients in program, visiting clients in their homes; monitoring adherence to medications and doing initial assessment for clients' support. Having been clients themselves, they act as a good source of peer support to fellow clients. Today $>1500$ clients on ART are home visited weekly by 45 (CATTS).

Results General improvement in health of PLWHAs who act as role models in their own communities $>90 \%$ adherence to ART.Creation sense of family and community spirit to HIV/ AIDS regardless of sex, religion, race, tribe or social status. Reduced stigma and discrimination among PLWHAs and increased disclosure at family and community level.

Conclusion Replication of community Network for care in other community based organisation is very essential other success of community HIV/AIDS prevention programs.

\section{P6.21 THINKING OF NEW STRATEGIES TOWARDS THE END OF PRENATAL HIV IN ARGENTINA. MINISTRY OF HEALTH, AIDS AND STIS PROGRAM}

Silvina Vulcano, Bruno Miriam, Gaiano Alejandra, Núñez Fabio, Zala Carlos. Ministerio Nacional dSalud-Dirección de Sida e ITS, Caba, Argentina

\subsection{6/sextrans-2017-053264.672}

Introduction In the context of the National Strategic Plan for HIV-AIDS, STIs 2013-2017 and the responsibility assumed in the Strategy for Elimination of Mother-to-Child Transmission of HIV, Syphilis, the National Program compile the results of qualitative investigations were carried out by different professionals working in the public system to evaluate the possibility of defining and implementing effective and creative strategies to get better diagnosis and treatment to reduce prenatal HIV transmission.Generate new strategies of action and intervention to reduce the gap in the prenatal transmission of HIV and Congenital Syphilis in Argentina.

Methods We collected the results of four qualitative investigations: "HIV-AIDS: vertical transmission. Incidence of social and health factors "Representations around the vertical transmission of HIV/AIDS: the construction of meaning from the perspective of professionals and mothers of children with HIV/AIDS " "Women living with HIV/AIDS, maternity and mental health: social support, psychic suffering and relationship with health services" and "Qualitative study on the perspective of mothers residing in the provinces with the highest HIV prevalence in Argentina". The main conclusions of each study were analysed to interpret how to generate new lines of political organisation in health to reduce the prenatal transmission rate of $5 \%$ to $2 \%$.

Results The possible strategies proposed were: Include safety support from social workers, include of mental health practices as part of the comprehensive care of pregnant women with HIV, Decentralise the hospital level for follow-up and treatment in the prevention of prenatal HIV transmission, Active offer HIV testing of the pregnant woman's partner Involve civil society as promoters in the prevention and companions of families with HIV to improve access to the health system and promise a cooperative action work with the health system.

Conclusion The prenatal HIV elimination strategy is a complex network between different social actors and an efficient health system.

\section{P6.22 STRENGTHENING COMMUNITY ADVOCACY \& SOLIDARITY FOR HIV VACCINE RESEARCH}

Tian Johnson. African Alliance for HIV Prevention, Johannesburg, South African Republic

\subsection{6/sextrans-2017-053264.673}

Introduction AIDS vaccine research is complex; the role of an AIDS vaccine advocate is challenging. Explaining the hopeful, yet slow and complicated progress in AIDS vaccine research to non-scientific stakeholders requires someone with relatively deep knowledge of complex science, research process, and related technical issues. Likewise, the critical role of representing stakeholder concerns to AIDS vaccine researchers requires someone who can speak in language that commands scientist's attention and respect.

Methods Through the Vaccine Advocacy Resource Group (VARG) a global team of AIDS prevention research advocates play a critical liaison role in a highly complex scientific field. Since 2014, the VARG has been convened virtually largely through teleconferences and email to receive research updates, discuss advocates perspectives and priorities, and to move forward key actions. Since 2015 this engagement has increasingly happened in person at some of the worlds largest HIV Vaccine Trial gatherings, elevating the role of community based advocates in a traditionally scientific space.

Results These efforts have been impactful in terms of coalescing the team of vaccine-specific advocates, building VARG members skills and understanding to a certain degree, and preparing them for conferences and scientific meetings.

Conclusion This poster aims to demonstrate how building the capacity of community advocates on the science of HIV Prevention Research Advocacy, particularly how it relates to vaccine research can strengthen community ownership of clinical trials and result in AIDS competent communities long before the trial has ended, as that community continues to advocate for increased awareness of, access to and uptake of existing HIV and STI prevention options 